\title{
Effects of heat stress on ovarian functions and embryonic development: mechanism and potential strategies to alleviate these effects in dairy cows
}

\author{
Zvi Roth \\ Department of Animal Sciences, Robert H. Smith Faculty of Agriculture, Food and Environment, the \\ Hebrew University, Rehovot 76100, Israel
}

\begin{abstract}
Summary
Reduced reproductive performance of lactating cows during the summer is associated mainly with intensive genetic selection for high milk production, which places a great load on the thermoregulatory mechanism. Today, cooling is the predominant strategy used to alleviate the effects of heat stress. However, it cannot eliminate the decline in reproduction. A better understanding of the mechanism by which heat stress compromises fertility is required to develop new strategies to mitigate its effects. This review summarizes what is known about the multifactorial effect of thermal stress on reproductive functions, which includes alterations in the hypothalamuspituitary-ovarian axis: gonadotropin secretion, follicular development, steroid production and corpus luteum function. The review provides some new insights into the cellular and molecular responses of oocytes and embryos to elevated temperature, discusses some potential underlying mechanisms, such as nuclear and cytoplasmic maturation, mitochondrial function, apoptotic pathways and oxidative stress, and suggests potential approaches to alleviating these effects. Given the complexity of heat-stress effects on reproduction, comprehensive reproductive management during the summer is suggested, based on: (1) an efficient cooling system as a prerequisite for any other strategies, (2) hormonal treatment targeted to specific subgroups of cows that will benefit from it, rather than the whole herd, and (3) combining two or more strategies in a program, rather than correcting the function of a single aspect of the reproductive system.
\end{abstract}

\section{Introduction}

Reduced reproductive performance of lactating cows during the summer is well-documented. Given the intensive genetic selection for high milk production and the concomitant global climate warming, fertility problems are expected to worsen in the coming years. Heat stress 
is not confined only to hot climates. For example, Japan has experienced unusual summer weather over the past few decades leading to reduced production and reproduction in lactating cows in temperate-climate regions such as Hokaido (Kadokawa et al. 2012). Moreover, the effects of heat stress are not limited to the hot months as they carry over to the following cooler months, resulting in long-term effects through the year which inflict heavy economic losses on the dairy industry.

The most common strategy to alleviate the effect of heat stress is to provide shade and evaporative cooling, based on combining sprinkling and ventilation in both the holding pen (before milking) and the feeding area (after milking). In Israel, this approach was successfully implemented 22 years ago in a large dairy herd. Cooling management based on seven 30-min cooling periods a day enabled maintenance of normal body temperature $\left(<39.0^{\circ} \mathrm{C}\right)$ in cows producing $30 \mathrm{~kg}$ milk/day, and conception rates (CRs) similar to those in the winter (Wolfenson et al. 1988). However today, intensive cooling consisting of 10 periods for a total of 7 cumulative $\mathrm{h} /$ day prevents the decline in milk production in extremely high-yielding cows $(>13,000 \mathrm{~kg} /$ year) but not that in summer reproduction. The summer-to-winter milk-production ratio in Israel is 0.985 , whereas CR is lower by 22 percentage units in the summer vs. winter (Flamenbaum \& Galon 2010). Nevertheless, efficient cooling management is a prerequisite for other, additional strategies to improve reproductive responses under heat stress.

This review will discuss the potential mechanism by which heat stress impairs reproductive features, focusing on its deleterious effects on ovarian function and embryonic development. New insights into heat-induced cellular and molecular alterations associated with oocyte maturation and developmental competence are presented. The review summarizes strategies that are known to alleviate the effects of heat stress. It also provides some practical guides for implementing reproductive management during the hot season.

\section{Effect of heat stress on ovarian function}

Among the components of the female reproductive tract, the ovary is highly sensitive to thermal stress. Given their lengthy developmental process, the ovarian pool of follicles and their enclosed oocytes have the potential to be exposed to environmental stressors, the most studied being thermal stress. Impaired growth and function of the small antral follicles can be expressed weeks later by compromised functioning of the dominant and preovulatory follicles. These alterations might in turn impair the cascade of events leading to ovulation and formation of the corpus luteum $(\mathrm{CL})$. Moreover, while heat stress can directly affect the developing embryos, it can also affect embryonic development indirectly by attenuating oocyte developmental capacity.

\section{Effects of heat stress on the follicles}

The follicular stages that are susceptible to thermal stress have not been precisely defined. Roth et al. (2000) suggested that early antral follicles of approximately $0.5-1.0 \mathrm{~mm}$ in diameter are sensitive to heat stress. In Gir cows, a 28-day period of heat stress reduced oocyte competence for 105 days (de Torres-Júnior et al. 2008), indicating that alterations occur at the small-antral follicle stage. Heat stress impairs the growth of medium-size follicles (6-9 mm), reduces the size of the first- and second-wave dominant follicles (Badinga et al. 1993, Wilson et al. 1998a,b), and attenuates dominance. These alterations are reflected in an increased number of mediumand large-size follicles, reduced concentration of inhibin and increased follicle-stimulating hormone (FSH) in the plasma (Badinga et al. 1993, Wolfenson et al. 1995, Roth et al. 2000). 
Alterations in follicular development are tightly associated with changes in the endocrine milieu. Seasonal studies have reported lower steroid concentrations in the follicular fluid obtained from large follicles, reduced granulosa-cell viability and impaired aromatase activity during the hot season (for review see Wolfenson et al. 2000). Follicle pieces obtained from heat-stressed cows secrete lower levels of androstenedione and oestradiol upon gonadotropin stimulation (Bridges et al. 2005), most likely due to decreased expression of luteinizing hormone (LH) receptors and reduced follicular response to LH (Ozawa et al. 2005). Alterations in steroidogenic capacity carry over from the summer to the autumn, as reflected by relatively low oestradiol content in the follicular fluid in late summer and increased levels throughout the autumn (Roth et al. 2001b, Roth et al. 2004). This transient effect is highly important because induction of frequent follicular waves during the autumn can enhance this spontaneous improvement (Roth et al. 2004). Similarly, the idea that hormonal manipulation of follicle turnover will improve fertility was recently tested by Friedman et al. (2011; Fig. 1): induction of three consecutive 9-day follicular waves during the summer and fall improved CR (37 vs. 53\% for control and treated cows, respectively) in primiparous but not multiparous cows. Treatment also increased the percentage of primiparous cows that were pregnant

a

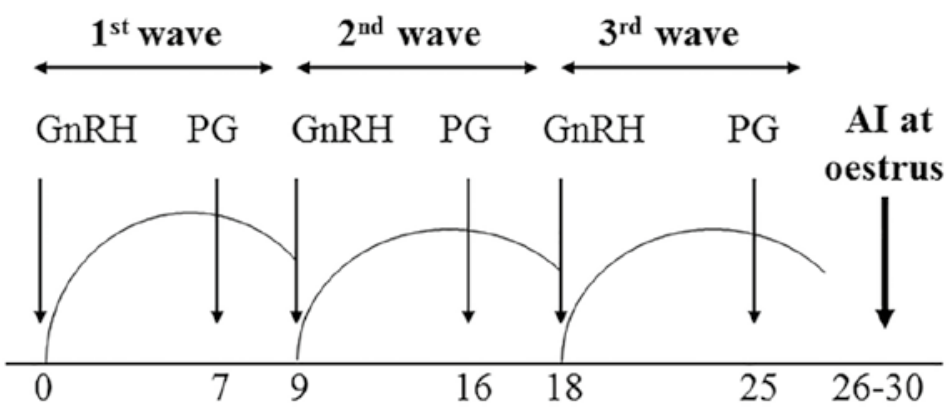

Day of treatment

b

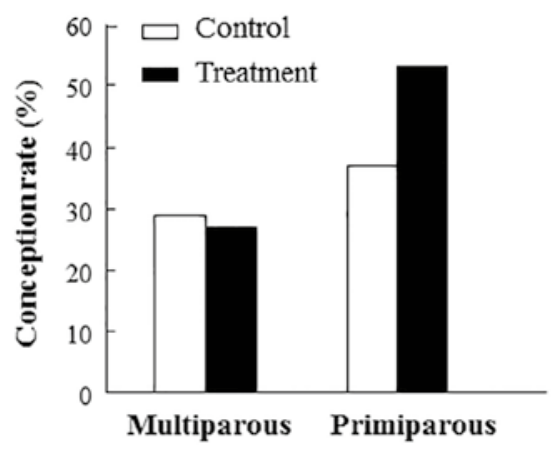

c

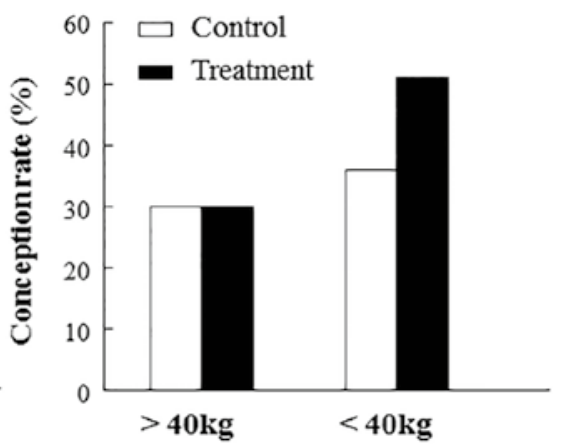

Fig. 1. Follicular turnover to improve fertility of lactating cows during the summer. (a) Schematized treatment protocol: cows 50 to 60 DIM were administered $\mathrm{GnRH}$ (day = 0 ) followed by PGF $2_{\alpha}$ on day 7 to induce three successive 9-day follicular waves. Cows were inseminated at oestrus and pregnancy diagnosis was performed 40 to 50 days postinsemination. Treatment increased conception rates in (b) primiparous cows and (c) cows with milk production $<40 \mathrm{~kg}$. Mean values are presented. 
at 120 days in milk (DIM) (51 vs. 65\% for control and treated cows, respectively). Treatment was more effective for cows with a high body condition score (BCS) or low somatic cell count (SCC) than for cows with a low BCS or high SCC. As in that study, only $60 \%$ of the cows responded to the treatment (i.e., showed oestrus within 5 days of the expected time), fertility could have been improved with timed Al. It seems that hormonal manipulation to induce follicular turnover might be beneficial for some subgroups of cows while utilizing efficient cooling management.

Among the potentially adverse effects of heat stress associated with low oestradiol levels are impairment of oestrus duration and intensity, increased incidence of anoestrus, silent ovulation, and reduced number of mounts (Gwazdauskas et al. 1981). Poor oestrus detection can be improved by using modern aids such as the Heat-Watch system, a radio-telemetric pressure transducer and pedometric oestrus detection (Nebel et al. 2011). Alternatively, utilization of ovulationsynchronization protocols ending with timed Al procedures can improve rate of pregnancies per Al (Moore \& Thatcher 2006). Nevertheless, timed Al cannot overcome the negative effects of heat stress on conception, as heat-stress alterations involve impairment in oocyte developmental competence and development of early-cleaving embryos. These might be better overcome by a timed embryo transfer procedure, which bypasses the effects of heat stress on these sensitive developmental stages (Hansen 2013a,b).

Reduced oestradiol concentrations during the follicular phase may also affect the preovulatory LH surge, and disrupt the cascade of events leading to oocyte ovulation. These, in turn, might lead to the development of non-ovulatory follicles and formation of ovarian cysts or alternatively, affect the formation and functioning of the CL. Suppression of pulsatile LH release and the preovulatory LH surge has been reported in hot climates (Wise et al. 1988). Heat-stressed cows with low oestradiol concentrations expressed a low-amplitude GnRH-induced LH surge (Gilad et al. 1993). Nonetheless, GnRH administration at the onset of oestrus (Ullah et al. 1996, Kaim et al. 2003) increased CR in mainly primiparous, and less in multiparous heat-stressed cows.

\section{Effect of heat stress on oocyte developmental competence}

Mammalian oocytes are arrested at the prophase stage of the first meiotic division and acquire their meiotic competence and fertilization potential in a stepwise manner during follicular development. Perturbations in the physiology of the follicle-enclosed oocyte during the lengthy period of follicular development can potentially lead to an oocyte with reduced competence for fertilization and subsequent development. Oocytes harvested from cows during the summer exhibit reduced ability to develop to the blastocyst stage after in-vitro fertilization (Al-Katanani et al. 2002) or chemical activation (Zeron et al. 2001). A period of two to three oestrous cycles is required for recovery from summer heat damage and appearance of competent oocytes in the subsequent fall (Roth et al. 2001a). A similar form of recovery has been shown in mice, where the effects of induced maternal hyperthermia carried over through three pregnancy cycles (Aroyo et al. 2007).

Gendelman et al. (2010) reported that the ratio between 2- and 4-cell-stage embryos (42 $\mathrm{h}$ postfertilization) was higher in the hot season (May-November) than in the cold season (DecemberApril), indicating a delay in the two first embryonic divisions. As early-cleaving zygotes are more competent to develop to the blastocyst stage than their late-cleaving counterparts, it appears that embryos developed from oocytes collected in the hot season have inferior developmental competence. Moreover, findings indicate that not only the individual ovulated oocyte, but also the ovarian pool of germinal vesicle (GV)-stage oocytes is impaired during heat exposure. Payton et al. (2004) examined the effect of heat shock on oocytes held at the GV stage using S-roscovitine, a cell-cycle inhibitor. While exposure to $41^{\circ} \mathrm{C}$ did not impair GV breakdown, it reduced the proportion of oocytes that progressed to metaphase II (MII) and those that developed to blastocysts. 
Similarly, preculturing with $75 \mu \mathrm{M}$ 3-isobutyl-1-methylxanthine (IBMX) maintained meiotic arrest by elevating CAMP concentrations in the oocyte. Exposing IBMX-blocked oocytes to heat shock $\left(41.2^{\circ} \mathrm{C}\right)$ reduced the proportion of oocytes that developed to the blastocyst stage, similar to the reduction reported for seasonal thermal stress (Gendelman \& Roth 2012a). The same study provided new insight into the molecular alterations resulting from heat shock in the GV-stage oocytes. Both seasonal and induced thermal stress impaired the expression of maternal transcripts (MOS, GDF9, POU5F1 and GAPDH) involved in oocyte maturation and early embryonic development (Fig. 2a). Although it was the GV-stage oocyte that was exposed to the thermal stress, the effect of heat stress on POU5F1 expression first appeared in MIl-stage oocytes and further in embryos, before (i.e. 2-, 4-, and 8-cell stages) and after (i.e. 8-16-cell stage) embryonic genome activation (Fig. $2 b$ ). The maternal mRNA stored in the oocyte is critical during the period of oocyte maturation, fertilization, and first embryonic divisions, until the embryonic genome becomes fully functional.

a

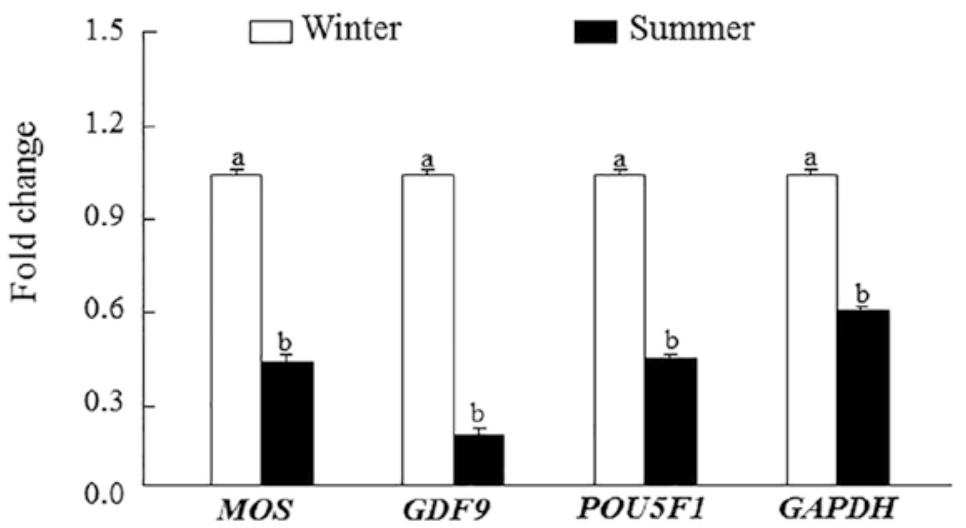

b

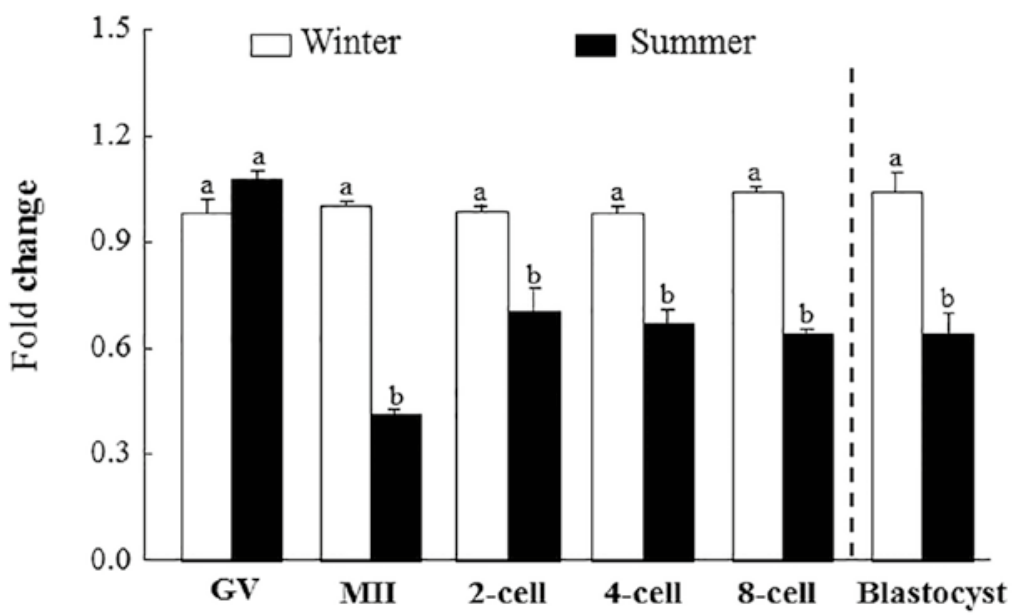

Fig. 2. Seasonal variations in transcript levels in oocytes and preimplantation embryos. (a) Transcript levels of MOS, GDF9, POU5F1, and GAPDH in MIl-stage oocytes collected in hot and cold seasons. (b) Transcript level of POU5F1 in GV- and MII-stage oocytes and in cleaved embryos before (2-, 4- and 8-cell) and after (blastocyst) embryonic genome activation. Data from real-time PCR, presented as means \pm SEM; $P<0.05$. 
The level of POU5F1 governs embryo fate and a critical amount of POU5F1 protein is required to sustain embryonic stem cells (Niwa et al. 2000). Thus, the low expression of POU5F1 found in embryos during the hot season could explain their low developmental competence.

Given the substantial damage caused by heat stress to the ovarian pool of oocytes, enhanced removal of the damaged follicles has been suggested. Frequent follicle aspirations by an ovum pick-up procedure improved the morphology and developmental competence of oocytes aspirated in the fall (Roth et al. 2001a). Hormonal treatment with FSH increased the number of growing follicles (Friedman et al. 2010) and the proportion of grade-1 oocytes and those cleaved to the 2-cell stage (Roth et al. 2002). Similarly, short-term administration of bovine somatotropin (bST) increased the proportion of grade-1 oocytes, but it did not improve cleavage rate or blastocyst formation (Roth et al. 2002).

Both somatotropin and IGF-I receptors are expressed in ovarian follicles and immature oocytes (Longergan et al. 2000). Under thermoneutral conditions, low doses (325 mg) of bST during the pre- and peri-implantation periods (days 0 and 14 post insemination) reduced embryonic losses and improved fertility (Ribeiro et al. 2013). Exposure of dairy cows to heat stress decreased plasma IGF-I concentration in association with reduced oocyte quality (de Rensis \& Scaramuzzi 2003). It is therefore reasonable to assume that bST administration to increase IGF-I might mitigate the deleterious effects of heat stress. However, a single injection of bST (500 mg) at insemination did not improve fertility of hyperthermic cows (Bell et al. 2008). In-vitro studies have reported that physiological doses $(12.5 \mathrm{ng} / \mathrm{mL})$ of IGF-I reduce the deleterious effect of heat shock on GV-stage oocytes and improve their cellular and developmental competence (Paula-Lopes et al. 2013). On the other hand, non-physiological doses of IGF-I (100 ng/mL) did not improve (Paula-Lopes et al. 2013), and even had a negative effect (Zhandi et al. 2009) on developmental competence. While its effect on the oocyte is not clear-cut, IGF-I has been shown to reduce the negative effects of heat shock on 5-day-old embryos. Moreover, transferring in-vitro-derived embryos treated with IGF-I resulted in a higher pregnancy rate in the summer (Jousan \& Hansen 2007).

\section{Effect of heat stress on nuclear and cytoplasmic maturation}

Thermal stress does not affect only the maternal mRNA; it also compromises other cellular characteristics of oocytes. Through maturation, the oocytes undergo multinuclear and cytoplasmic events, all associated with oocyte developmental competence (Eppig 1996). These include reorganization of the cytoskeletal filaments, resumption of meiosis, and redistribution of cytoplasmic organelles such as mitochondria, cortical granules and endoplasmic reticulum (Ferrieria et al. 2009; Yamada \& Isaji 2011). Exposing bovine oocytes to heat shock during maturation impairs both microtubulin and microfilaments, which are involved in both nuclear and cytoplasmic organelle transport. As a result, most heat-shocked oocytes that fail to undergo maturation and fertilization are arrested at the MI to MII stages (Roth \& Hansen 2005). Heat-shock induced perturbations of the spindle apparatus in bovine (Ju et al. 2005, Roth \& Hansen 2005), porcine (Ju \& Tseng 2004) and parthenogenetically activated bovine oocytes (Tseng et al. 2004). With respect to cytoplasmic events, heat shock impaired cortical granule translocation (Payton et al. 2004) and mitochondrial distribution in oocytes (Gendelman \& Roth 2012b) and 2-cellstage embryos (Rivera et al. 2004). Cortical granule relocation is the mechanism underlying the elimination of polyspermy, whereas maternal mitochondrial storage is the primary energy source for embryo growth to the blastocyst stage. Taken together, these alterations might lead to fertilization failure. 
Mitochondrial dysfunction in heat-shocked oocytes

Mitochondrial activity and membrane potential are key indicators of cellular viability. Mitochondrial membrane potential reflects the pumping of hydrogen ions across the inner membrane via the processes of electron transport and oxidative phosphorylation. Exposing GV-stage and maturing oocytes to heat shock reduces oocytes' mitochondrial activity and mitochondrial membrane potential in cumulus cells (Paula-Lopes et al. 2012). Similarly, the proportion of oocytes with high mitochondrial membrane potential is relatively low during the summer (Gendelman \& Roth 2012b). New evidence for season-induced alterations in the expressions of both nuclear (SDHD and ATP5B) and mitochondrial (MT-ND2, MT-CYB, COX2) genes has been recently provided by Gendelman and Roth (2012b). These genes are crucial in the oxidative-phosphorylation process and therefore, alterations in their expression might impair the number of active components in the electron transport chain and in turn lead to reduced ATP levels. Supporting this assumption, oocyte maturation with $50 \mu \mathrm{M}$ CoQ10 a ubiquitous free-radical scavenger and a key component of the mitochondrial respiratory chain, increased the proportion of polarized mitochondria and enhanced the proportion of embryos that developed to the blastocyst stage in the fall, to a level similar to that achieved in the winter (Gendelman \& Roth 2012b; Fig. 3).

a
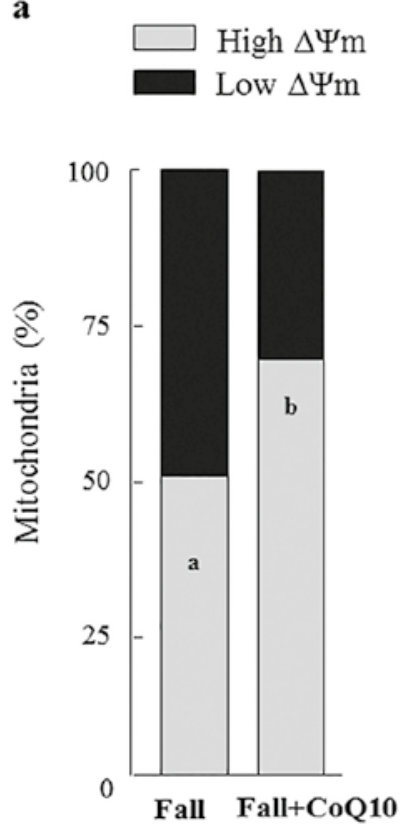

b
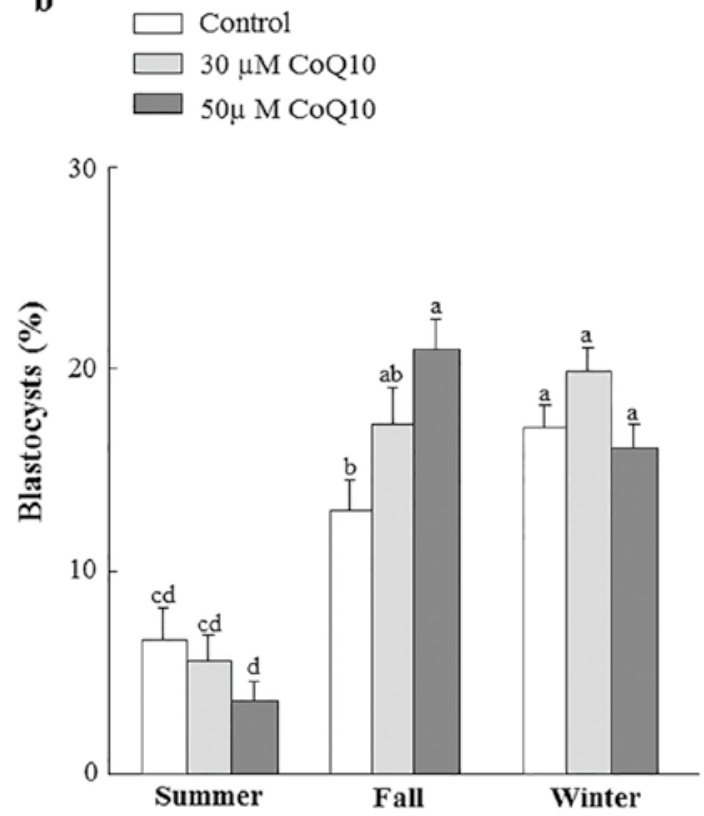

Fig. 3. Effect of CoQ10, a ubiquitous free-radical scavenger, on mitochondrial function and developmental competence of oocytes collected in the fall. (a) Proportion of high-polarized mitochondrial membranes $(\Delta \psi \mathrm{m})$ in Mll-stage oocytes. (b) Proportion of oocytes developed to 8-day blastocyst. Data are presented as means \pm SEM; $P<0.05$.

\section{Heat-shock-induced apoptosis in oocytes}

Heat-induced alterations in mitochondrial functioning are associated with the activation of apoptotic cascades through intrinsic mitochondrial pathways. Exposing oocytes to $41^{\circ} \mathrm{C}$ 
during maturation decreased the proportion of oocytes with low mitochondrial membrane potential and TUNEL-positive chromatin (Soto \& Smith 2009). Similarly, heat shock during maturation increased the proportion of oocytes expressing high activity of group II caspases (i.e., caspases 2, 3 and 7) and nuclear apoptotic fragmentation (Roth \& Hansen 2004a,b). The mitochondrial apoptotic pathway involves cell-membrane alterations, such as phosphatidylserine externalization at an early phase of the apoptotic cascade (Lahorte et al. 2004) and activation of the sphingomyelin pathway, resulting in DNA damage (Hannun \& Luberto 2000). Kalo and Roth (2011) linked heat-induced alterations in the oocyte phospholipid membrane and oocyte developmental competence. Alterations included hydrolysis of membrane sphingomyelin, ceramide generation and phosphatidylserine externalization (Annexin- $\mathrm{V}$ assay). Roth and Hansen (2004b) reported that the anti-apoptotic molecule S1P blocks the effect of heat shock on bovine oocytes, by modulating the ceramide-S1P balance. Specific inhibitors-fumonisin B1 to block dihydroceramide synthase and desipramine hydrochloride to block acid sphingomyelinasewere used to inhibit ceramide formation through de-novo and hydrolytic pathways, respectively (Kalo \& Roth 2011). Use of these inhibitors alleviated, to some extent, the effect of heat shock and support the notion that thermal-stress-induced apoptosis via ceramide formation is functionally related to the reduced developmental competence of bovine oocytes.

The amount of lipid in the ruminant oocyte is relatively high and consists of $50 \%$ triacylglycerol, $20 \%$ phospholipid, 20\% cholesterol and 10\% free fatty acids (McEvoy et al. 2000). Thus, lipid metabolism, in particular that of sphingomyelins, might offer a number of opportunities for modifying oocyte responses to heat shock. In particular, ceramide can be produced de novo from condensation of serine with palmitoyl-CoA (Jenkins et al. 2002) and therefore, dietary manipulations that affect the membrane fatty acid composition or reduce ceramide formation might improve oocyte quality. Zeron et al. (2001) reported that oocyte membrane composition is affected by season, and is characterized by decreased polyunsaturated fatty acids during the summer. Feeding ewes with polyunsaturated fatty acids increased the proportion of highquality oocytes in that season (Zeron et al. 2002). Similarly, in-vitro supplementation of palm oil Ca-LCFA increased the proportion of oocytes developing to blastocysts (Fouladi-Nashta et al. 2007). Nevertheless, dietary fatty acids administered during the summer did not have any effect on in-vitro developmental competence of oocytes aspirated from lactating cows (Bilby et al. 2006).

\section{Hyperthermia-induced oxidative stress}

Hyperthermia-induced oxidative stress is suggested to be one of the processes by which environmental stress disrupts reproductive performance in mammals. Ozawa et al. (2002) reported that exposing zygotes to heat shock, either directly or through maternal hyperthermia, causes early embryonic loss and is associated with reduced levels of the cytosolic antioxidant glutathione (GSH). Elevated body temperature increases intracellular reactive oxygen species (ROS) in bovine oocytes (Nabenishi et al. 2012) and preimplantation embryos (Sakatani et al. 2004), and decreases GSH concentration in mouse embryos (Matsuzuka et al. 2004). The balance between pro- and antioxidants plays a pivotal role in the follicle: spontaneous resumption of meiosis is inhibited by antioxidants and may be induced by an increase in ROS (Takami et al. 1999). On the other hand, high ROS levels within the follicle are associated with increased cytoplasmic defects and abnormal chromosomal segregation (Van Blerkom et al. 1997). Therefore, it is reasonable to assume that heat-induced perturbations of this balance are involved in disruption of the developmental competence of follicle-enclosed oocytes. Moreover, 
administration of exogenous antioxidants has been suggested to overcome the adverse effects of heat stress on fertility. Nevertheless, vitamins A, E and C, provided either as nutritional supplements or intramuscularly, did not have any beneficial effect in heat-stressed cows (Ealy et al. 1994, Aréchiga et al. 1998, Paula-Lopes et al. 2003). Similarly, supplementation of vitamin E to the culture medium failed to improve in-vitro-derived bovine embryos under heat shock (Ealy et al. 1994, 1995, Paula-Lopes et al. 2003). On the other hand, in-vitro administration of anthocyanin and dithiothreitol was reported to protect embryos from heat shock (Sakatani et al. 2007, Castro e Paula \& Hansen 2008). Aréchiga et al. (1998) reported that feeding supplemental $\beta$-carotene for at least 90 days beginning at $\sim 15$ days after calving increased the proportion of cows that were pregnant at 120 days postpartum by 14 percentage units, suggesting that long-term rather than periodic administration is needed.

Using a mouse model, Roth et al. (2008) showed that in-vivo administration of the antioxidant epigallocatechin gallate (EGCG), the most abundant flavonoid component of green tea, can moderate some of the deleterious effects induced by maternal hyperthermia. Pretreatment with EGCG at a dose of $100 \mathrm{mg} / \mathrm{kg}$ body weight increased the proportion of early cleaved embryos and the percentage of blastocysts that formed and hatched. In addition, pretreatment with EGCG reduced the apoptotic status of preimplantation embryos, most likely as a result of its antioxidative, antiapoptotic and/or membrane-stabilizing activities within the antral follicles. Matsuzuka et al. (2005) showed that administration of melatonin, another potent ROS scavenger, to heat-stressed mice alleviates hyperthermia-induced early embryonic death. A recent study reported that treatment of dairy cows with melatonin implants before calving improved their reproductive performance in the summer as it reduced days open and the number of Als per pregnancy (Garcia-Ispierto et al. 2013). Taken together, although oxidative stress appears to be involved in the mechanism by which hyperthermia disrupts the oocyte, use of exogenous antioxidants to manipulate the animal's oxidative status has not yet been implemented in practice.

\section{Heat stress and early embryonic development}

Much of the effect of heat stress involves changes in ovarian function. However, studies indicate that preimplantaion embryos are also sensitive to elevated temperatures in a stage-dependent manner. Embryos at early developmental stages are more susceptible to thermal stress and then become more resistant at later developmental stages (Hansen 2007a,b). Exposing cows to elevated temperatures between onset of oestrus and insemination (Putney et al. 1988) or on day 1 after oestrus (but not on days 3, 5 or 7) decreased the development and viability of embryos on day 8 (Ealy et al. 1993). Similarly, induction of heat shock blocked the development of 2-cell-stage embryos, had a moderate effect on 4- to 8-cell-stage embryos and only a limited effect on the morulae (Hansen 2007a). A change in the balance between ROS generation and GSH level has been recently suggested to underlie acquisition of embryonic thermotolerance (Hansen 2013b).

Embryo-transfer procedures can bypass the thermosensitive developmental stages (for review see Hansen 2013b). Various studies have reported that embryo transfer during the summer results in pregnancy rates similar to those achieved with $\mathrm{Al}$ or embryo transfer in the winter. One major limitation of this approach is the poor survival of embryos following freezing. The percentage of pregnancies during the hot season was greater for cows receiving in-vitro-derived fresh, but not frozen, embryos (Ambrose et al. 1999, Drost et al. 1999). On the other hand, transferring in-vivo-derived frozen-thawed embryos increased pregnancy rates for recipient cows relative 
to artificially inseminated ones (Putney et al. 1989). However, when the recipient could not maintain normal body temperature, pregnancy rate following embryo transfer was compromised (Vasconcelos et al. 2006). Use of an efficient cooling system to maintain normothermia in the recipient cows is thus highly important as it might alleviate the deleterious effects of heat stress on the uterus and plasma progesterone concentrations.

\section{Effect of heat stress on the $C L$ and progesterone level}

Formation of a functioning $\mathrm{CL}$ following ovulation is obligatory for pregnancy maintenance. Thus, heat-induced alteration in luteal function and reduced progesterone $\left(\mathrm{P}_{4}\right)$ concentration in the circulation is another mechanism suggested to reduce embryo survival and to increase early embryonic loss. Plasma $\mathrm{P}_{4}$ concentrations during the summer are lower than those during the spring or winter (Howell et al. 1994, Wolfenson et al. 2002). Chronic seasonal exposure has a deleterious carryover effect on follicular function that leads to the formation of a suboptimal $\mathrm{CL}$ and low $\mathrm{P}_{4}$ concentration in the plasma (Wolfenson et al. 2000). An in-vitro study suggested that luteal insufficiency is the result, at least in part, of previous exposure of the preovulatory follicle to thermal stress and decreased production of $\mathrm{P}_{4}$ by follicular cells, in particular theca cells (Wolfenson et al. 2002).

As a delayed increase in postovulatory $\mathrm{P}_{4}$ and low concentrations during the preimplantation stages can lead to early embryonic losses (Mann \& Lamming 2001), various studies have attempted to moderate the deleterious effects of heat stress on luteal function by inducing an accessory $\mathrm{CL}$ and excess luteal tissue. Administration of human chorionic gonadotropin (hCG) on day 5 or 6 post-Al did not affect CR (Schmitt et al. 1996) or increased it by 13 percentage units (Beltran \& Vasconcelos 2008). On the other hand, administration of GnRH between days 5 and 15 post-Al increased conception rate by approximately 15 percentage units (Willard et al. 2003; López-Gatius et al. 2006), whereas others found no improvement in summer fertility (Franco et al. 2006). Differences among studies could be related to variations in the day of hCG or GnRH administration or to severity and duration of the thermal stress.

Supplementation of exogenous $\mathrm{P}_{4}$ at the very early stages of pregnancy has the potential to increase embryo survival and improve conception in cows. Under normothermal conditions, $\mathrm{P}_{4}$ supplementation during the early (days 5 to 9), but not late (days 12 to 16) luteal phase increased trophoblast length and Interferon- $\tau$ production on day 16 postfertilization (Mann et al. 2006). Friedman et al. (2012) recently reported that administration of a controlled intravaginal drug-releasing (CIDR) device on day $5 \pm 1$ post-Al for 13 days had a substantial effect on CR in the summer when the device was inserted on day 4, relative to days 5 or $6(43,39$ and $34 \%$, respectively). Importantly, cows with low BCS at peak lactation, or those diagnosed with postpartum reproductive disorders, or both, gained significant benefit from the CIDR implant (Fig. 4). It should be noted that cows were maintained under normothermic to temporary mild hyperthermic conditions.

\section{Conclusion}

In-vitro and in-vivo studies explored the multifactorial effects of heat stress on ovarian function (Fig. 5). These effects include alterations in follicular growth, steroid production and hormonal secretion, and reduction in oocyte and embryonic developmental competence. Cooling is a prerequisite for any additional strategy and should be performed over long periods of time. Similarly, periodic administration of antioxidant is not efficient at protecting the follicle and 
a

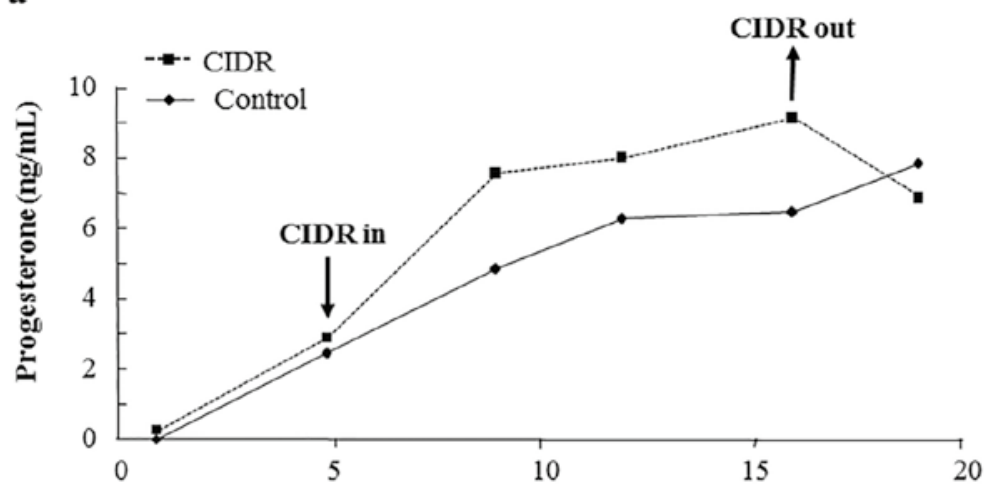

Day in cycle

b

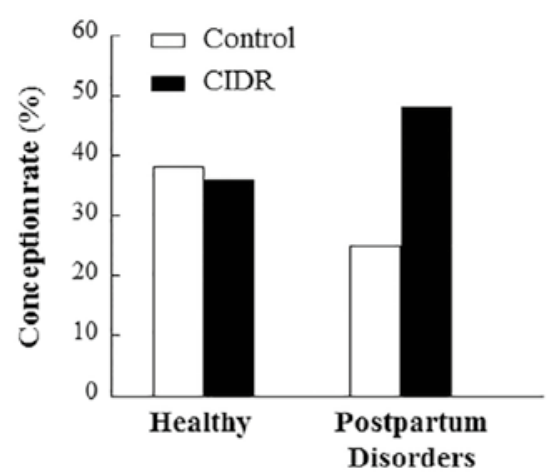

c

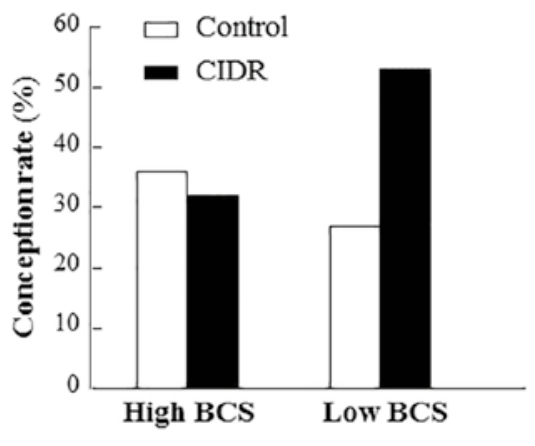

Fig. 4. CIDR inserted post-Al to improve conception rate during the summer and fall. Cows were treated with insert containing $1.9 \mathrm{~g}$ of $\mathrm{P}_{4}$ on day $5 \pm 1$ post-Al for 13 days. Analysis revealed (a) a day-by-treatment interaction $(P<0.06)$, with approximately $1.5 \mathrm{ng} / \mathrm{mL}$ greater progesterone concentration in plasma from day 9 to 16 of the cycle. (b) Interaction $(P=$ 0.035 ) between treatment and low BCS at peak lactation, reflected by a 26-percentageunit increase in conception rate. (c) A 23-percentage-unit increase in conception rate in cows treated with CIDR and diagnosed with postpartum reproductive disease. Data are presented as means.

its enclosed oocytes. Hormonal treatments with $\mathrm{GnRH}_{\mathrm{PG}}$ to induce follicular turnover were found successful for a subpopulation of cows (primiparous, high BCS, low SCC), but had only a limited impact on the herd as a whole. The deleterious effect of heat stress on CL function can be mitigated by insertion of a CIDR device 5 days post-AI to increase $\mathrm{P}_{4}$ levels in order to support the developing embryo, and this has been found to be beneficial for a subgroup of cows with postpartum uterine diseases. The effect of heat stress on the oocyte and earlycleaved embryos can be bypassed by thermoresistant embryo transfer. Nevertheless, to date, none of these suggested approaches have been widely implemented on farms. It is proposed that combining two or more of these potential approaches into one program might be more efficient for improving reproductive responses under heat stress. For example, combining hormonal treatments before $\left(\mathrm{GnRH} / \mathrm{PG}_{2 \alpha}\right)$ and after (CIDR) insemination would compensate for 


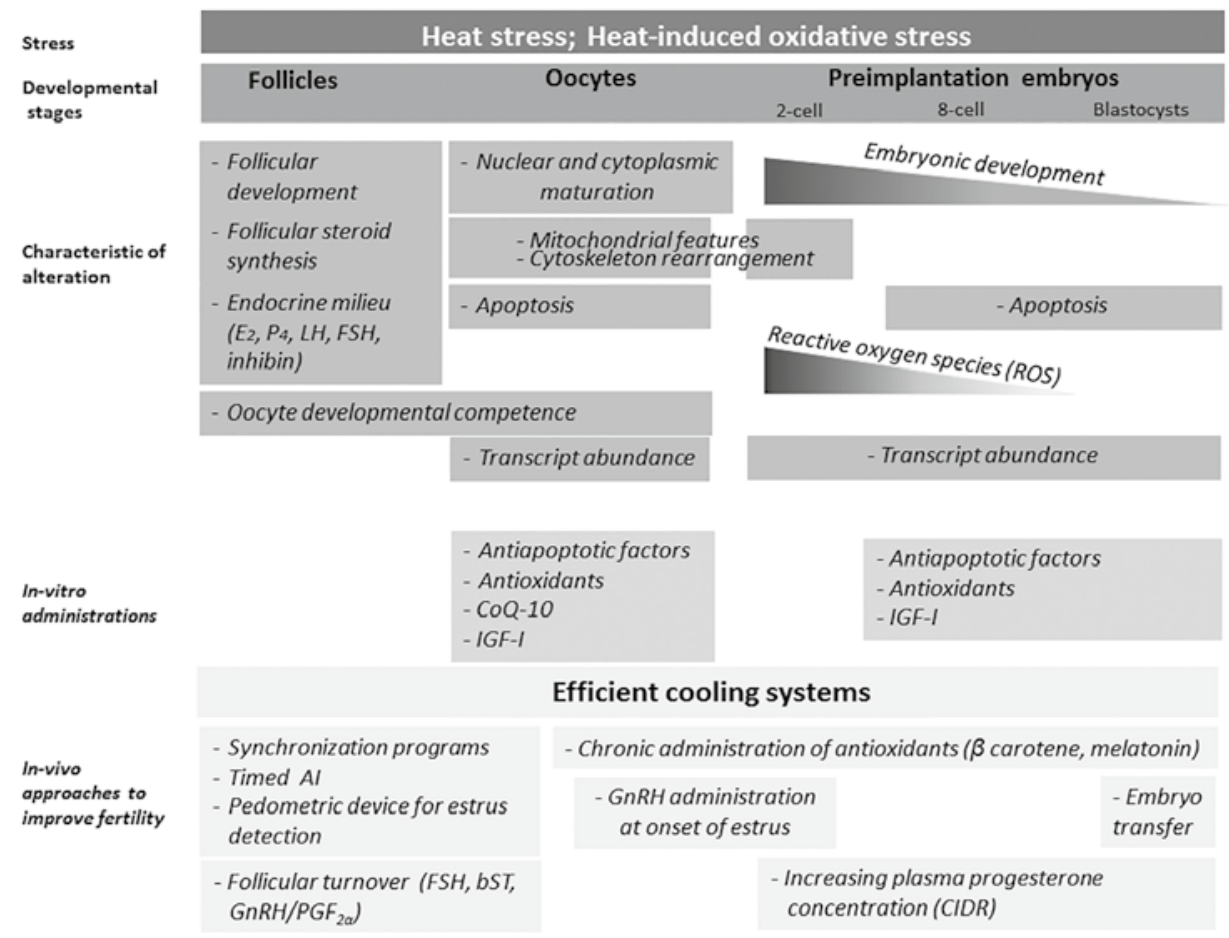

Fig. 5. Diagram illustrating the effects of heat stress and heat-induced oxidative stress on oocyte and embryo competence at various developmental stages. Also presented are various compounds that can be administered to counteract the effects of heat shock in vitro, and some potential approaches to improving fertility. Heat stress can impair follicular development and steroid synthesis, which in turn can disrupt the endocrine milieu. Heat stress also affects oocyte maturation and developmental competence, as reflected by impaired nuclear, cytoplasmic maturation and cytoskeletal rearrangement during maturation, as well as altered mitochondrial features and transcript abundance. Heat-induced apoptosis has been documented in matured oocytes and preimplantation embryos, but not in the 2-cell-stage embryo. The embryo is more susceptible to thermal stress and reactive oxygen species (ROS) in the early stages of development and becomes more thermotolerant coincident with activation of the embryonic genome. In-vitro administration of antiapoptotic, antioxidant and growth factors can counteract the effects of heat shock on the oocyte and embryo. However, these have not yet seen practical use. Various approaches have been examined to improve the fertility of lactating cows under heat stress. While an efficient cooling system is required to maintain cows in normothermia, it is not sufficient to improve fertility. Other suggested approaches, to be combined with cooling, are: (1) hormonal administration to induce follicular turnover; (2) transfer of in-vitro-derived embryos treated with IGF-I. In both approaches, increasing plasma progesterone concentration to support the developing embryo might help increase conception rate during the summer.

the deleterious effects of summer heat stress on two different reproductive tissues, the ovarian pool of follicles and their enclosed oocytes and the $C L$, respectively. This program has been found to extend the population of cows that benefit by 16 percentage units relative to each treatment alone (Z Roth et al., unpublished observations). It is suggested that a comprehensive strategy, rather than correcting the function of a single part of the reproduction tract, is required to cope with the whole heat-stress problem. 


\section{References}

Al-Katanani YM, Paula-Lopes FF \& Hansen PJ 2002 Effect of season and exposure to heat stress on oocyte competence in Holstein cows. Journal of Dairy Science 85 390-396.

Ambrose JD, Drost M, Monson RL, Rutledge JJ, LeibfriedRutledge ML, Thatcher MJ, Kassa T, Binelli M, Hansen PJ, Chenoweth PJ \& Thatcher WW 1999 Efficacy of timed embryo transfer with fresh and frozen in vitro produced embryos to increase pregnancy rates in heat-stressed dairy cattle. Journal of Dairy Science 82 2369-2376.

Aréchiga CF, Staples CR, McDowell LR \& Hansen PJ 1998 Effects of timed insemination and supplemental betacarotene on reproduction and milk yield of dairy cows under heat stress. Journal of Dairy Science 81 390-402.

Aroyo A, Yavin S, Arav A \& Roth Z 2007 Maternal hyperthermia disrupts developmental competence of follicle-enclosed oocytes: in vivo and ex vivo studies in mice. Theriogenology 67 1013-1021.

Badinga L, Thatcher WW, Diaz T, Drost M\& Wolfenson D 1993 Effect of environmental heat stress on follicular development and steroidogenesis in lactating Holstein cows. Theriogenology 39 797-810.

Bell A, Rodríguez OA, de Castro E Paula LA, Padua MB, Hernández-Cerón J, Gutiérrez CG, De Vries A \& Hansen PJ 2008 Pregnancy success of lactating Holstein cows after a single administration of a sustained-release formulation of recombinant bovine somatotropin. BMC Veterinary Research 422.

Beltran MP \& Vasconcelos JLM 2008 Conception rate in Holstein cows treated with $\mathrm{GnRH}$ or hCG on the fifth day post artificial insemination during summer. Arquivo Brasileiro de Medicina Veterinária e Zootecnia 60 580586.

Bilby TR, Block J, do Amaral BC, Sa Filho O, Silvestre FT, Hansen PJ, Staples CR \& Thatcher WW 2006 Effects of dietary unsaturated fatty acids on oocyte quality and follicular development in lactating dairy cows in summer. Journal of Dairy Science 89 3891-3903.

Bridges PJ, Brusie MA \& Fortune JE 2005 Elevated temperature (heat stress) in vitro reduces androstenedione and estradiol and increases progesterone secretion by follicular cells from bovine dominant follicles. Domestic Animal Endocrinology 29 508-522.

Castro e Paula LA \& Hansen PJ 2008 Modification of actions of heat shock on development and apoptosis of cultured preimplantation bovine embryos by oxygen concentration and dithiothreitol. Molecular Reproduction and Development 75 1338-1350.

de Rensis F \& Scaramuzzi RJ 2003 Heat stress and seasonal effects on reproduction in the dairy cow-a review. Theriogenology 60 1139-1151.

de S Torres-Júnior R, de FA Pires $M$, de Sá WF, de M Ferreira A, Viana JHM, Camargo LSA, Ramos AA, Folhadella IM, Polisseni J, de Freitas C, Clemente CAA, de Sá Filho MF, Paula-Lopes FF \& Baruselli PS 2008 Effect of maternal heat-stress on follicular growth and oocyte competence in Bos indicus cattle. Theriogenology 69 155-166.

Drost M, Ambrose JD, Thatcher MJ, Cantrell CK, Wolfsdorf KE, Hasler JF \& Thatcher WW 1999 Conception rates after artificial insemination or embryo transfer in lactating dairy cows during summer in Florida. Theriogenology 52 1161-1167.

Ealy AD, Drost M \& Hansen PJ 1993 Developmental changes in embryonic resistance to adverse effects of maternal heat stress in cows. Journal of Dairy Science 76 2899-2905.

Ealy AD, Arechiga CF, Bray DR, Risco CA \& Hansen PJ 1994 Effectiveness of short-term cooling and vitamin $E$ for alleviation of infertility induced by heat stress in dairy cows. Journal of Dairy Science 77 3601-3607.

Ealy AD, Howell JL, Monterroso VH, Arechiga CF \& Hansen PJ 1995 Developmental changes in sensitivity of bovine embryos to heat shock and use of antioxidants as thermoprotectants. Journal of Dairy Science 73 14011407.

Eppig JJ 1996 Coordination of nuclear and cytoplasmic oocyte maturation in eutherian mammals. Reproduction Fertility and Development 8 485-489.

Ferreira EM, Vireque AA, Adona PR, Meirelles FV, Ferriani RA \& Navarro PA 2009 Cytoplasmic maturation of bovine oocytes: structural and biochemical modifications and acquisition of developmental competence. Theriogenology 71 836-848.

Flamenbaum I \& Galon N 2010 Management of heat stress to improve fertility in dairy cows in Israel. Journal of Reproduction and Development 56 Suppl S36-41.

Fouladi-Nashta AA, Gutierrez CG, Gong JG, Garnsworthy PC \& Webb R 2007 Impact of dietary fatty acids on oocyte quality and development in lactating dairy cows. Biology of Reproduction 77 9-17.

Franco MP, Thompson M, Brad AM \& Hansen PJ 2006 Effectiveness of administration of gonadotropin-releasing hormone at days 11, 14 or 15 after anticipated ovulation for increasing fertility of lactating dairy cows and nonlactating heifers. Theriogenology 66 945-954.

Friedman E, Glick G, Lavon Y \& Roth Z 2010 Effects of low-dose follicle-stimulating hormone administration on follicular dynamics and preovulatory follicle characteristics in dairy cows during the summer. Domestic Animals Endocrinology 39 106-115.

Friedman E, Voet H, Reznikov D, Dagoni I \& Roth Z 2011 Induction of successive follicular waves by $\mathrm{GnRH}$ and PGF2ם to improve fertility of lactating cows during the summer and autumn. Journal of Dairy Science $\mathbf{9 4}$ 2393-2402.

Friedman E, Roth Z, Voet H, Lavon Y \& Wolfenson D 2012 Progesterone supplementation postinsemination improves fertility of cooled dairy cows during the summer. Journal of Dairy Science 95 3092-3099.

Garcia-Ispierto I, Abdelfatah A \& López-Gatius F 2013 Melatonin treatment at dry-off improves reproductive performance postpartum in high-producing dairy cows under heat stress conditions. Reproduction in Domestic Animals 48 577-583.

Gendelman M \& Roth Z 2012a In vivo vs. in vitro models for studying the effects of elevated temperature on the GV-stage oocyte, subsequent developmental competence and gene expression. Animal Reproduction Sciences 134 125-134. 
Gendelman M \& Roth Z 2012b Incorporation of coenzyme Q10 into bovine oocytes improves mitochondrial features and alleviates the effects of summer thermal stress on developmental competence. Biology of Reproduction 87 1-12.

Gendelman M, Aroyo A, Yavin S \& Roth Z 2010 Seasonal effects on gene expression, cleavage timing, and developmental competence of bovine preimplantation embryos. Reproduction 140 73-82.

Gilad E, Meidan R, Berman A, Graber Y \& Wolfenson D 1993 Effect of heat stress on tonic and $\mathrm{GnRH}$-induced gonadotrophin secretion in relation to concentration of oestradiol in plasma of cyclic cows. Journal of Reproduction and Fertility 99 315-321.

Gwazdauskas FC, Thatcher WW, Kiddy CA, Paape MJ \& Wilcox CZ 1981 Hormonal patterns during heat stress following PGF(2)alpha-tham salt induced luteal regression in heifers. Theriogenology 16 271-285.

Hannun YA \& Luberto C 2000 Ceramide in the eukaryotic stress response. Trends in Cell Biology 10 73-80.

Hansen PJ 2007a To be or not to be; determinants of embryonic survival following heat shock. Theriogenology 68 40-48.

Hansen PJ 2007b Exploitation of genetic and physiological determinants of embryonic resistance to elevated temperature to improve embryonic survival in dairy cattle during heat stress. Theriogenology 68 242-249.

Hansen PJ 2013a Antecedents of mammalian fertility: lessons from the heat-stressed cow regarding the importance of oocyte competence for fertilization and embryonic development. Animal Frontiers 3 34-39.

Hansen PJ 2013b Cellular and molecular basis of therapies to ameliorate effects of heat stress on embryonic development in cattle. Animal Reproduction $10322-333$.

Howell JL, Fuquay JW \& Smith AE 1994 Corpus luteum growth and function in lactating Holstein cows during spring and summer. Journal of Dairy Science 77 735-739.

Jenkins GM, Cowart LA, Signorelli P, Pettus BJ, Chalfant CE \& Hannun, YA 2002 Acute activation of de novo sphingolipid biosynthesis upon heat shock causes an accumulation of ceramide and subsequent dephosphorylation of SR proteins. Journal of Biological Chemistry 277 42572-42578.

Jousan FD \& Hansen PJ 2007 Insulin-like growth factor-I promotes resistance of bovine preimplantation embryos to heat shock through actions independent of its antiapoptotic actions requiring PI3K signaling. Molecular Reproduction and Development 74 189-196.

Ju JC \& Tseng JK 2004 Nuclear and cytoskeletal alterations of in vitro matured porcine oocytes under hyperthermia. Molecular Reproduction and Devlopoment 68 125-133.

Ju JC, Jiang S, Tseng JK, Parks JE \& Yang X 2005 Heat shock reduces developmental competence and alters spindle configuration of bovine oocytes. Theriogenology 64 1677-1689.

Kadokawa H, Sakatani M \& Hansen PJ 2012 Perspectives on improvement of reproduction in cattle during heat stress in a future Japan. Animal Science Journal 83 439-445.

Kaim M, Bloch A, Wolfenson D, Braw-Tal R, Rosenberg M, Voet H \& Folman Y 2003 Effects of GnRH administered to cows at the onset of estrus on timing of ovulation, endocrine responses and conception. Journal of Dairy Science 86 2012-2021.

Kalo D \& Roth Z 2011 Involvement of the sphingolipid ceramide in heat-shock-induced apoptosis of bovine oocytes. Reproduction Fertility and Development 23 876-888.

Lahorte CMM, Vanderheyden JL, Steinmetz N, Van de Wiele C, Dierckx RA \& Slegers G 2004 Apoptosisdetecting radioligands: current state of the art and future perspectives. European Journal of Nuclear Medicine and Molecular Imaging 31 887-919.

Longergan P, Gutierrez-Adan A, Pintado B, Fair T, Ward F, Fuente JD \& Boland M 2000 Relationship between time of the first cleavage and the expression of IGF-I growth factors, its receptor, and two housekeeping genes in bovine two-cell embryos and blastocysts produced in vitro. Molecular Reproduction and Development 57 146-152.

López-Gatius F, Santolaria P, Martino A, Delétang F \& De Rensis F 2006 The effects of $\mathrm{GnRH}$ treatment at the time of $\mathrm{Al}$ and12 days later on reproductive performance of high producing dairy cows during the warm season in northeastern Spain. Theriogenology 65 820-830.

Mann GE \& Lamming GE 2001 Relationship between maternal endocrine environment, early embryo development and inhibition of the luteolytic mechanism in cows. Reproduction 121 175-180.

Mann GE, Fray MD \& Lamming GE 2006 Effects of time of progesterone supplementation on embryo development and interferon-tau production in the cow. Veterinary Journal 171 500-503.

Matsuzuka T, Ozawa M, Hirabayashi M, Ushitani A \& Kanai Y 2004 Developmental competence and glutathione content of maternally heat-stressed mouse oocytes and zygotes. Animal Science Journal 75 117-124.

Matsuzuka T, Sakamoto N, Ozawa M, Ushitani A, Hirabayashi M \& Kanai Y 2005 Alleviation of maternal hyperthermia-induced early embryonic death by administration of melatonin to mice. Journal of Pineal Research 39 217-223.

McEvoy TG, Coull GD, Broadbent PJ, Hutchinson JS \& Speake BK 2000 Fatty acid composition of lipids in immature cattle, pig and sheep oocytes with intact zona pellucida. Journal of Reproduction and Fertility 118 163-170.

Moore K \& Thatcher WW 2006 Major advances associated with reproduction in dairy cattle. Journal of Dairy Science 89 1254-1266.

Nabenishi H, Takagi S, Kamata H, Nishimoto T, Morita T, Ashizawa K \& Tsuzuki Y 2012 The role of mitochondrial transition pores on bovine oocyte competence after heat stress, as determined by effects of cyclosporin A. Molecular Reproduction and Development 79 31-40.

Nebel RL, Jones CM \& Roth Z 2011 Reproduction, events and management mating management: detection of estrus. In Encyclopedia of Dairy Sciences, second edn, vol 4, pp 461-466. Eds JW Fuquay, PF Fox \& PLH McSweeney. San Diego: Academic Press.

Niwa H, Miyazaki J \& Smith AG 2000 Quantitative expression 
of Oct-3/4 defines differentiation, dedifferentiation or selfrenewal of ES cells. Nature Genetics 24 372-376.

Ozawa M, Hirabayashi M \& Kanai Y 2002 Developmental competence and oxidative state of mouse zygotes heat-stressed maternally or in vitro. Reproduction 124 683-689.

Ozawa M, Tabayashi D, Latief TA, Shimizu T, Oshima I \& Kanai Y 2005 Alterations in follicular dynamics and steroidogenic abilities induced by heat stress during follicular recruitment in goats. Reproduction 129 621630.

Paula-Lopes FF, Al-Katanani YM, Majewski AC, McDowell LR \& Hansen PJ 2003 Manipulation of antioxidant status fails to improve fertility of lactating cows or survival of heat-shocked embryos. Journal of Dairy Science $\mathbf{8 6}$ 2343-2351.

Paula-Lopes FF, Lima RS, Risolia PHB, Ispada J, Assumpcao MEOA \& Visintin JA 2012 Heat stress induced alteration in bovine oocytes: functional and cellular aspects Animal Reproduction 9 395-403.

Paula-Lopes FF, Lima RS, Satrapa RA \& Barros CM 2013 Physiology and Endocrinology Symposium: Influence of cattle genotype (Bos indicus vs. Bos taurus) on oocyte and preimplantation embryo resistance to increased temperature. Journal of Animal Science 91 1143-1153.

Payton RR, Romar R, Coy P, Saxton AM, Lawrence JL \& Edwards JL 2004 Susceptibility of bovine germinal vesicle stage oocytes from antral follicles to direct effects of heat stress in vitro. Biology of Reproduction 71 1303-1308.

Putney DJ, Drost M \& Thatcher WW 1988 Embryonic development in superovulated dairy cattle exposed to elevated ambient temperatures between Days 1 to 7 post insemination. Theriogenology 33 195-209.

Putney DJ, Drost M \& Thatcher WW 1989 Influence of summer heat stress on pregnancy rates of lactating dairy cattle following embryo transfer or artificial insemination. Theriogenology 31 765-778.

Ribeiro ES, Bruno RG, Farias AM, Hernández-Rivera JA, Gomes GC, Surjus R, Becker LF, Birt A, Ott TL, Branen JR, Sasser RG, Keisler DH, Thatcher WW, Bilby TR \& Santos JE 2013 Low doses of bovine somatotropin enhance conceptus development and fertility in lactating dairy cows. Biology of Reproduction (in press).

Rivera RM, Kelley KL, Erdos GW \& Hansen PJ 2004 Reorganization of microfilaments and microtubules by thermal stress in two-cell bovine embryos Biology of Reproduction 70 1852-1862.

Roth Z \& Hansen PJ 2004a Involvement of apoptosis in disruption of developmental competence of bovine oocytes by heat shock during maturation. Biology of Reproduction 71 1898-1906.

Roth Z \& Hansen PJ 2004b Sphingosine-1-phosphate protects cultured bovine oocytes from heat shock during maturation. Biology of Reproduction 71 2072-2078.

Roth Z \& Hansen PJ 2005 Disruption of nuclear maturation and rearrangement of cytoskeletal elements in bovine oocytes exposed to heat shock during maturation. Reproduction 129 235-244.

Roth Z, Meidan R, Braw-Tal R \& Wolfenson D 2000 Immediate and delayed effects of heat stress on follicular development and its association with plasma FSH and inhibin concentration in cows. Journal of Reproduction and Fertility 120 83-90.

Roth Z, Arav A, Bor A, Zeron Y, Braw-Tal R \& Wolfenson D 2001a Improvement of quality of oocytes collected in the autumn by enhanced removal of impaired follicles from previously heat-stressed cows. Reproduction 122 737-744.

Roth Z, Meidan R, Braw-Tal R, Shaham-Albalancy A \& Wolfenson D 2001b Delayed effect of heat stress on steroidogenesis in bovine medium-size and preovulatory follicles. Reproduction 121 745-751.

Roth Z, Arav A, Bor A, Zeron Y, Braw-Tal R \& Wolfenson D 2002 Effect of treatment with FSH or bST on the quality of oocytes aspirated in the autumn from previously heatstressed cows. Journal of Dairy Science 85 1398-1405.

Roth Z, Bor A, Braw-Tal R \& Wolfenson D 2004 Carry-over effect of summer thermal stress on characteristics of the preovulatory follicle of lactating cows. Journal of Thermal Biology 29 681-685.

Roth Z, Aroyo A, Yavin S \& Arav A 2008 The antioxidant epigallocatechin gallate (EGCG) moderates the deleterious effects of maternal hyperthermia on follicle-enclosed oocytes in mice. Theriogenology 70 887-897.

Sakatani M, Kobayashi S \& Takahashi M 2004 Effects of heat shock on in vitro development and intracellular oxidative state of bovine preimplantation embryos. Molecular Reproduction and Development 67 77-82.

Sakatani M, Suda I, Oki T, Kobayashi S, Kobayashi S \& Takahashi M 2007 Effects of purple sweet potato anthocyanins on development and intracellular redox status of bovine preimplantation embryos exposed to heat shock. Journal of Reproduction and Development 53 605-614.

Schmitt EJ, Diaz T, Barros CM, de la Sota RL, Drost M, Fredriksson EW, Staples CR, Thorner R \& Thatcher WW1996 Differential response of the luteal phase and fertility in cattle following ovulation of the first-wave follicle with human chorionic gonadotropin or an agonist of gonadotropin-releasing hormone. Journal of Animal Science 74 1074-1083.

Soto P \& Smith LC 2009 BH4 peptide derived from Bcl$\mathrm{xL}$ and Bax-inhibitor peptide suppresses apoptotic mitochondrial changes in heat stressed bovine oocytes. Molecular Reproduction and Development 76 637-646.

Takami M, Preston SL, Toyloy VA \& Behrman HR 1999 Antioxidants reversibly inhibit the spontaneous resumption of meiosis. American Journal of Physiology 276 684-688.

Tseng JK, Chen CH, Chou PC, Yeh SP\& Ju JC 2004 Influences of follicular size on parthenogenetic activation and in vitro heat shock on the cytoskeleton in cattle oocytes. Reproduction in Domestic Animals 39 146-153.

Ullah G, Fuquay JW, Keawkhong T, Clark BL, Pogue DE \& Murphey EJ 1996 Effect of gonadotropin-releasing hormone at estrus on subsequent luteal function and fertility in follicular and oocyte competence under heat stress. Journal of Dairy Science 79 1950-1953.

Van Blerkom J, Antczak M \& Schrader R 1997 The developmental potential of the human oocyte is related 
to the dissolved oxygen content of follicular fluid: association with vascular endothelial growth factor levels and perifollicular blood flow characteristics. Human Reproduction 12 1047-1055.

Vasconcelos, JL, Demétrio DG, Santos RM, Chiari JR, Rodrigues CA \& Sá Filho OG 2006 Factors potentially affecting fertility of lactating dairy cow recipients. Theriogenology 65 192-200.

Willard S, Gandy S, Bowers S, Graves K, Elias A \& Whisnant C 2003 The effects of GnRH administration postinsemination on serum concentrations of progesterone and pregnancy rates in dairy cattle exposed to mild summer heat stress. Theriogenology 59 1799-1810.

Wilson SJ, Kirby CJ, Koenigsfeld AT, Keisler DH \& Lucy MC 1998a Effects of controlled heat stress on ovarian function of dairy cattle. 2. Heifers. Journal of Dairy Science $\mathbf{8 1}$ 2132-2138.

Wilson SJ, Marion RS, Spain JN, Spiers DE, Keisler DH \& Lucy MC 1998b Effects of controlled heat stress on ovarian function of dairy cattle. 1. Lactating cows. Journal of Dairy Science $812124-2131$.

Wise ME, Armstrong DV, Huber JT, Hunter R \& Wiersma F 1988 Hormonal alterations in the lactating dairy cow in response to thermal stress. Journal of Dairy Science 71 2480-2485.

Wolfenson D, Flamenbaum I \& Berman A 1988 Hyperthermia and body energy store effects on estrous behavior, conception rate, and corpus luteum function in dairy cows. Journal of Dairy Science 71 3497-3504.

Wolfenson D, Thatcher WW, Badinga L, Savio JD, Meidan R, Lew BJ, Braw-Tal R \& Berman A 1995 Effect of heat stress on follicular development during the estrous cycle in lactating dairy cattle. Biology of Reproduction 52 1106-1113.
Wolfenson D, Roth Z \& Meidan R 2000 Impaired reproduction in heat-stressed cattle: basic and applied aspects. Animal Reproduction Science 61 535-547.

Wolfenson D, Sonego H, Bloch A, Shaham-Albalancy A, Kaim M, Folman Y \& Meidan R 2002 Seasonal differences in progesterone production by luteinized bovine thecal and granulosa cells. Domestic Animal Endocrinology 22 81-90.

Yamada M\& Isaji Y 2011 Structural and functional changes linked to, and factors promoting, cytoplasmic maturation in mammalian oocytes. Reproductive Medicine Biology 10 69-79.

Zeron Y, Ocheretny A, Kedar O, Borochov A, Sklan D \& Arav A 2001 Seasonal changes in bovine fertility: relation to developmental competence of oocytes, membrane properties and fatty acid composition of follicles. Reproduction 121 447-454.

Zeron Y, Sklan D \& Arav A 2002 Effect of polyunsaturated fatty acid supplementation on biophysical parameters and chilling sensitivity of ewe oocytes. Molecular Reproduction and Development 61 271-278.

Zhandi M, Towhidi A, Nasr-Esfahani MH, Eftekhari-Yazdi P \& Zare-Shahneh A 2009 Unexpected detrimental effect of insulin like growth factor-1 on bovine oocyte developmental competence under heat stress. Journal of Assisted Reproduction and Genetics 26 605-611. 